\title{
Retroperitoneal Tumours - Treatment and Prognosis of Tumour Recurrence
}

\author{
OVIDIU GABRIEL BRATU1,2,3, ALEXANDRU IONUT CHERCIU2*, ADRIAN BUMBU4, SORIN LUPU5, DRAGOS RADU MARCU1,2, \\ FLORENTINA IONITA RADU ${ }^{6}$, MARIA MANEA 7 , CRISTIAN FURAU ${ }^{8}$, CAMELIA CRISTINA DIACONU ${ }^{1,9}$, \\ DAN LIVIU DOREL MISCHIANU ${ }^{1,2,3}$ \\ University of Medicine and Pharmacy Carol Davila, 8 Eroii Sanitari Str, 050474, Bucharest, Romania \\ 2Department of Urology, Emergency Universitary Central Military Hospital, 88 Mircea Vulcanescu Str, 010825, Bucharest, Romania \\ ${ }^{3}$ Academy of Romanian Scientists, 54 Splaiul Independentei, 030167, Bucharest, Romania \\ 4University of Medicine and Pharmacy, 10 Piata 1 Decembrie Str., 410073, Oradea, Romania \\ ${ }^{5}$ Emergency Clinical County Hospital, 25 Calea Bucuresti, 500326, Brasov, Romania \\ ${ }^{6}$ Department of Gastroenterology, Emergency Universitary Central Military Hospital, 88 Mircea Vulcanescu Str, 010825, Bucharest, \\ Romania \\ Department of Cardiology, Emergency Universitary Central Military Hospital, 88 Mircea Vulcanescu Str, 010825, Bucharest, \\ Romania \\ ${ }^{8}$ Department of Obstetrics and Gynecology, Arad County Clinical Hospital, 24 Andreny Karoly Str., 310037, Arad, Romania \\ 'Department of Internal Medicine, Clinical Emergency Hospital of Bucharest, 8 Calea Floreasca, 014461, Bucharest, Romania
}

\begin{abstract}
Retroperitoneal tumors, once considered uncommon, have been reported in the last years in such numbers that they cannot be considered anymore a rare condition. Tumor recurrence following surgical excision is quite common and a tumor that was considered originally as benign in many cases can recur as a malignant tumor. The purpose of this paper is to underline the difficulties in terms of establishing a correct diagnosis and a proper therapeutic protocol when facing a retroperitoneal mass of unknown origin, as well as to present the available data regarding prognosis, treatment options and tumor recurrence. Retroperitoneal tumors can be classified as benign or malignant; solid, cystic or both; single or multiple, and of varied histological types. A high percentage of patients with retroperitoneal tumors are discovered in advanced stages, usually seeking medical help for symptoms related to nearby organ compression/invasion. This pathology requires a prompt and adequate multidisciplinary management, in order to achieve disease control and to reduce the recurrence rate. Complete surgical resection is the potential curative treatment for retroperitoneal tumors and it is bestmanaged in high-volume centers, bya multidisciplinary team. Complete oncological tumor resection and tumorgrade remain the most important predictors for local recurrence and disease-specific survival. Further research is required in order to define the role of radiotherapy, as well as to discovernew biological therapies that target various molecular pathways involved in retroperitoneal cancers.
\end{abstract}

Keywords: retroperitoneal tumors, prognostic, recurrence

Retroperitoneal tumors are a group of tumors that occur in the anatomical space named retroperitoneal space. Vital structures such as liver, stomach, pancreas, ipsilateral colon and mesocolon are strongly connected with the retroperitoneal space [1]. The posterior limit of the retroperitoneal space is represented by the psoas, transverse abdominal, iliacus and quadratus lumborum muscles, but depending on the tumors position and dimensions, it may be formed by the diaphragm, ipsilateral kidney, ureters and gonadal vessels. The spine, paraspinous muscles, inferior vena cava (for right-sided tumors) and aorta (for left-sided tumors) form the medial limits, while the lateral ones are represented by the lateral abdominal musculature and, depending on the tumors' location, itmay include the kidney and colon. The inferior limit is formed by the iliopsoas muscle, the femoral nerve, the iliac vessels or the pelvic sidewall, while the upper limit of the retroperitoneal space is represented by the diaphragm, the right lobe of the liver, the duodenum, the pancreas or the spleen [2].

There are three categories of retroperitoneal tumours:

-Primary unattached tumours.

-Tumours arising in organs normally present in the retroperitoneal space.
-Primary or metastatic tumors, involving the retroperitoneal lymph nodes.

\section{Primary unattached tumors}

Retroperitoneal tumors, once considered uncommon, have been reported in the last years in such numbers that they cannot be considered anymore a rare condition. They can be classified as benign or malignant tumors; solid, cystic, or both; single or multiple, and of varied histologic types. Recurrence following surgical excision is quite common for this type of tumors and a tumor originally regarded as being benign, in many cases can recur as a malignant tumor. According to a study conducted by Hansmann and Budd [1], the retroperitoneal tumors frequently originate from the embryological remnants of the urogenital tract. Their conclusion was based on the multiple correlations observed between the histological types, as well as on the resemblance of these tumors with the tumors encountered in adult urogenital organs. This concept has been accepted over the years. Another type of tumoral tissue may arise from the adult tissue normally present in the retroperitoneal space, such as fibrous connective tissue, fat, nerves, and ganglia, as well as from blood vessels or lymphatic tissue. 
The current article will discuss the retroperitoneal malignant tumors, depending on their histopathological type and characteristics.

\section{Sarcoma}

\section{Fibrosarcoma}

Adult-type fibrosarcoma is an aggressive and rare subgroup of soft tissue sarcomas. The diagnosis is in most cases an exclusion one, due to the multitude of other spindle-cell shaped sarcomas. The probability of misdiagnosis between similar tumor entities is high and it may lead to improper tumor management. Fibrosarcoma is characterized by a high rate of recurrence and a low sensitivity at radio- and chemotherapy [3].

Soft tissue sarcomas can be divided into five histopathological groups, such as: pleomorphic pattern, myxoid pattern, small round cell pattern, epitheloid cell pattern and spindle cell pattern. Spindle cell sarcomas represent almost half of all sarcomas. Fibrosarcoma is a constituent of the spindle cell type of soft tissue sarcomas, buthistopathology alone is notenough for a clear distinction between fibrosarcoma and other spindle-cell neoplasms. Immunohistochemistry (IHC) can be used in such cases, in order to obtain a certain diagnosis of fibrosarcoma, using specific antibody reagents which allow the detection of important tumor markers. A tumor marker is a molecule, such as oncofetal antigens, cell surface antigens, receptors, enzymes, hormones, oncogenes or cytoplasmatic proteins found on the tumor cell surface, in the surrounding tumor microenvironment, in blood or urine. They tumor markers can be secreted in high quantities by the body, as a reaction to the tumor presence, or by the malignant cells themselves. Tumor markers have important functions in terms of therapy monitoring, as well as in monitoring of tumor recurrence, being crucial for the differential diagnosis of fibrosarcoma $[4,5]$.

The prognosis of fibrosarcomas and soft tissue sarcomas is influenced by multiple factors, such as: patient's age, tumor depth and size, malignant nature of the tumor, involvement of bones, nerves, vessels, nearby organs, collagen density, as well as the metastatic potential and appearance of tumour recurrences $[6,7]$.

Unfavorable prognostic factors of fibrosarcomas consist of: high histologic grade, large amount of tissue necrosis ( $>50 \%$ ), high number of mitotic processes ( $>20 / 10 \mathrm{hpf}$ ), a decrease of collagen fibers in favor of an increased cellularity, deep localized tumors, tumors larger than $5 \mathrm{~cm}$ $[4,6]$. Histopathological grading is considered to be the most important prognostic indicator $[6,8]$. High-grade fibrosarcoma patients, with great risk for metastases, will most likely benefit from adjuvant therapy [9]. Multiple studies have shown that approximately $80 \%$ of adult-type fibrosarcomas are found to be high-grade malignancies and that the overall 5 -year survival rate ranges between 40 and $60 \%$, regardless of the tumors grade $[4,9,10]$. It has been reported that approximately $60 \%$ of the patients with low-grade tumors reach 10 years survival after the initial diagnosis, this percentage being much lower for the patients with high grade tumors, only $30 \%$ of them surviving 10 years after the diagnosis. Depending on the tumor grade, the patient's age and the histology of the tumor margin, the recurrence rate varies between $12 \%$ and $79 \%$ [11].

An accurate diagnosis is essential for a proper treatment strategy. Therefore, assesing the typical features of the tumor is importantfor an accurate diagnosis. New markers used nowadays, such as miRNA expression profiles, may represent an important diagnostic step in the identification of fibrosarcoma.
According to literature, the survival rate of a patient with adult-type fibrosarcoma is poor, because of the aggressive nature of the tumor. The best prognosis is seen in the following situations: complete surgical tumor resection, with histological tumor-free margins (R0); the use of agents that can lead to a reduction in tumor cell proliferation and migration, as well as inducing remission via neoadjuvant or adjuvant therapy; preventing tumor invasion and metastasis $[10,11]$.

Surgery represents the first-line therapy for patients with localized soft tissue sarcomas [12]. The type of intervention and its success depend on the tumor's location, its size and grade of malignancy [7]. In case of intramuscular localized soft tissue tumors, the involved muscle compartment should be resected en-bloc, as part of the so-called compartment resection. In those cases, adjuvant radiation therapy is not indicated. If, on the other hand, the tumors do not reach the muscle origin and its insertion, or in the case of an extracompartmental growth, a wide resection should be performed. In case of R1/R2 situations, a surgical reintervention should be performed, if possible [12].

Tumor cell proliferation and migration significantly correlate with the composition of the surrounding extracellular matrix (ECM) components. The high concentration of matrix metalloproteinases (MMPs) within the tumor tissue results in an increased degradation of the ECM, which favors tumor cell growth, as well as its spread to distant sites. In these circumstances, intratumoral injections, especially of the recently developed TIMP-1-GPI fusion protein, can be a successful treatment strategy [13]. Other treatment options focus on the adjustments of the mechanisms which lead to CAM-DR [14].

Similar to other treatment strategies, the ones discussed above have their advantages and disadvantages. However, the efficacy of new treatment methods is likely to depend on the MMP profile inside the tumor tissue. Therefore, patients with fibrosarcoma may respond differently to new treatment methods [15].

\section{Leiomyosarcoma}

Leiomyosarcomas (LMS) are rare tumors originated from the mesenchymal cells, showing smooth muscle differentiation [16]. They usually appear in middle-aged or older persons, the uterus, as well as the retroperitoneal space, being the most common locations for this type of tumor. LMS may also arise from any large blood vessel, specifically the inferior vena cava. The typical LMS histological pattern consists of sharply marginated groups of spindle cells. Immunohistochemistry shows a pattern of Smooth Muscle Antibody (SMA) positivity, along with hcaldesmon and desmin staining. Other positive stains are: EMA (epithelial membrane antigen), keratin, CD34, and S100 protein [17].

The main modality of treatment is surgical resection, although many patients may have metastatic disease at presentation. Adjuvantradiotherapyis used for local control, but there is no proven survival advantage. Despite the firstline therapy, the 5-year rate of relapse is $40 \%$ [18]. Chemotherapy after complete tumor resection is controversial, a metaanalysis showing a significant benefit in overall survival [19].

LMS is a major challenge, being one of the most resistant tumors to conventional chemotherapies. Other treatment strategies, like cytokine signaling, along with those targeting angiogenesis and various pathways, have been generally unsatisfying. To date, agents that target DNA repair pathways in cancer have not been widely tested in 
sarcomas. In some settings, such agents show great promise in terms of treatment of cancers that, like LMS, show defects in the TP53 pathways or demonstrate genomic instability. The use of Poly(ADP-ribose) polymerase inhibitors (PARPi), either alone or in combination with cytotoxic agents, can be an option for future clinical trials in LMS $[18,19]$.

\section{Liposarcoma}

Retroperitoneal liposarcomas are one of the most challenging tumors, considering their disposition for local recurrence following surgical excision. In current practice, chemotherapy is futile for the majority of patients, so surgical resection is the most effective treatment modality for the majority of the patients. The status of negative surgical margins is reachable in over $80 \%$ of patients, when the use of en bloc resection is utilized $[20,21]$. This is considered an aggressive approach, but it yields a median survival of approximately 7 years and a 5 -year diseasespecific survival of $60 \%$ [22,23].

Histologic subtype is classified as well-differentiated, dedifferentiated, myxoid/round cell or pleomorphic. Retroperitoneal fat tumors contain mature adipocytes with occasional atypical cells, with irregular hyperchromatic nuclei, and rare or absent lipoblasts, or those lesions with lipoblasts and minimal fibrosis that have been labeled as lipoma-like well-differentiated liposarcoma. Tumors with atypical stromal cells associated with significant fibrosis ( $>25 \%$ ) were designated as sclerosing welldifferentiated liposarcoma. Lesions with regions of nonlipogenic spindle cell sarcoma, arising within a fatty tumor or in the bed of a previously resected low grade lipomatous tumor, were identified as dedifferentiated liposarcoma [24].

The histologic subtype, and hence tumor grade, are wellestablished factors determining the outcome of patients with primary retroperitoneal liposarcoma. However, studies on patients with locally recurrent disease have shown that the previously mentioned factors are not so important in determining disease-specific survival and local recurrence. It was demonstrated that the subtype and grade of the primary tumor do not maintain their importance as independent prognostic factors for survival [24].

\section{Tumors arising in organs normally present in the retroperitoneal space \\ Kidney \\ Kidney tumors are one of the biggest group of} retroperitoneal tumors. One of most frequently encountered malignant kidney tumor is the clear cell carcinoma. It is often detected incidentally during imaging investigations, or it may present as a palpable mass accompanied by hematuria and/or lumbar, abdominal discomfort/pain, decreased renal function [25], these signs and symptoms bringing these patients to seek medical attention. The other representatives, like granular cell and tubular carcinoma, are not so common and are generally more aggressive, since they are non-encapsulated, freegrowing tumors. Kidney sarcomas of any type must be regarded as a rarity. However, the most frequent kidney mixed tumor is the Wilms tumor, which is found during childhood. It should be considered when a palpable tumor is found in a child. According to Snyder et al, this type of tumor accounts for more than $50 \%$ of the retroperitoneal tumors discovered during childhood [26].

It is necessary to revise the treatment strategies when medical practice or advances in technology alter disease patterns. For kidney tumors less than $4 \mathrm{~cm}$, studies suggest that local control can be achieved successfully by using the surgical approach (radical nephrectomy, as well as partial nephrectomy) $[26,27]$. Small renal tumors may be resected by partial nephrectomy, with minimal morbidity, and a cancer-specific outcome equivalent to that of radical nephrectomy. Although the need for renal preservation in an individual with a normal contralateral kidney may seem unnecessary today, its apparent benefit may be well appreciated in the future, because it can decrease the risk of renal failure and the need for chronic dialysis [28]. However, studies revealed that local recurrence rate after partial nephrectomy was from 0 to $12 \%$ [29-31].

\section{Adrenal}

Depending on their origin, adrenal tumors can be classified as tumors descending from the medulla and as tumors originating from the adrenal cortex [32,33].

The adrenal medulla is made from cells of the neural canal, therefore the tumors that originate from it are nerve type tumors. The neuroblastoma is not a rare tumor and it occurs more frequently in children. It is a malignant type of tumor and quite often it manifests itself as a palpable, solid mass in the abdomen, although not rarely patients with this type of tumor seek medical help for symptoms related to metastases, especially to bone metastases. Approximately $50 \%$ of these tumors have specific stippled calcification on the X-ray. When pyelography is performed, most of them will show various degrees of renal displacement. The prognosis is poor, even though there are many possibilities of surgical removal. The rare medullary tumor named ganglioneuroma which is composed of ganglion cells, is not included in this classification.

Adrenal cortex carcinoma can be asymptomatic or it may be accompanied by signs related to nearby organ compression/ invasion. Recurrence and metastases from this type of tumor are common, and the prognosis is poor. Children with neuroblastoma have different outcomes, which depend on the stage of the disease, as well as on the patient's age.

There are evidences that neuroblastoma has a worse long-term prognosis, in spite of tumor stage and tumor location, and in some cases a more prolonged course. Even if the survival after $2-3$ years of evolution is better in older patients, because of the more slow evolution, in patients with stage 1 to 3 the ultimate survival rate is estimated to be less than $5 \%$. The number of older patients is very small, due to the rare incidence of neuroblastoma in this age interval. Only a few people remained disease-free, including patients with stage I, II, and III (localized or regional disease). In contrast, children with localized or regional disease, without MYCN amplification, present survival rates from $80 \%$ to $95 \%$. For patients with neuroblastoma diagnosed after early childhood, there are no standard treatment guidelines.

Studies and literature reviews present adolescents and adults with localized disease (stage I or II), who have been treated initially conservatively, in the past, and now they may benefit from more intensive therapy. Patients with advanced disease (stage III and IV) at diagnosis have had a constant and poor prognosis from the beginning, identical with younger children diagnosed with metastatic neuroblastoma. It is not demonstrated if long-term therapy or more intensive and agressive treatment will ultimately make a difference in the survival of these patients. More than that, biologic approaches, for example immunologic therapy and differentiating agents are currently being studied and someday may be used in these patients. It is 
also necessary that biologic studies of tumor tissue from adult patients to continue and to discover why these type of tumors behave differently and in the same time why they lack MYCN amplification, often being negative for catecholamine secretion [34, 35].

\section{Pancreas}

The pancreas is partially a retroperitoneal organ and pancreatic tumors often involve the retroperitoneal space. Pancreatic malignant tumors represent the 4th most common cause of death because of cancer, in spite of being the 13th type of cancer worldwide. The incidence and mortality rates are growing year by year, worldwide. It is a severe type of cancer, approximately $70 \%$ of patients having locally advanced or metastatic tumors at the moment of diagnosis, with multiple complications and severe pain, which require a multidisciplinary management in the perioperative period [36-38]. The overall survival of patients with locally advanced tumors is estimated to be approximately 4 months and 2 to 3 months for those with metastases. The overall survival rate of patients with pancreatic cancer has not improved over the past two decades [39].

Over the years, the screening techniques for pancreatic cancer have evolved and nowadays an important role have the serologic markers, which include: CA19-9, carcinoembryonic antigen (CEA), osteopontin (OPN), macrophage inhibitory cytokine 1 (MIC-1), and S100A6. These markers are also helpful in terms of evaluating the patient's prognosis and the treatment response.

Prognosis and treatment depend on the stage of cancer at the moment of diagnosis, so the correctstaging is critical. Staging is principally based on TNM classification for pancreatic cancer. Simplifying the staging system, these tumors may be classified in resectable, borderline resectable and unresectable tumors. Resectable tumors include stage I and stage II tumors [40,41].

Despite the improvements that have been made over the years in terms of diagnostic tests, the detection rate at an early stage, as well as the survival rate, remain low, usually being detected when complications occurs [42]. Nowadays, the efficacy of conventional chemotherapy and radiotherapy for pancreatic cancer is limited, surgical excision being the best option for these patients. Even if only $20 \%$ of cases with pancreatic cancer (PC) are operable, the surgery is the only possibility to cure PC. For the operative procedure, many factors mustbe considered, such as tumor location, tumor staging and tumor size.

For the patients in whom surgical excision is not indicated, because of the unresectable status of the pancreatic tumor, chemotherapy is the first-line treatment and it is extensively used. GEM/erlotinib, GEM/NABpaclitaxel, FOLFIRINOX, GEM/capecitabine and XELOX/ capecitabine/oxaliplatin are examples of chemotherapy regimens used in PC. However, $P C$ is defined by a reaction that promotes resistance to chemotherapy [43].

More than that, gene therapy is not yet applied in daily clinical practice, although there are evidences that it is successful in vitro and in vivo. The mechanism includes gene replacements, gene blockade and gene modification. Target for gene therapy are genes such as P21CIP1/WAF1, BCRP, K-ras, p14ARF, p16INK4A/CDKN2A, LSM1/ CaSm, VEGF, HER-2/EerB-2, and MDR1 [44-49]. New therapies are urgently needed because conventional treatments, like radiotherapy and chemotherapy, are useful in a small number of patients with PC. A bacterial cancer vaccine for $P C$, using an attenuated Listeria strain as vector, just begins to reach early-phase clinical trial [50].

\section{Tumors of Retroperitoneal Lymph Nodes}

Primary tumors developed from lymph nodes are an uncommon cause of a retroperitoneal tumor mass. These tumors may divert from any of the types presented in the classification. More common are metastatic retroperitoneal tumors or para-aortic lymph nodes and usually require a thorough differential diagnosis [51]. They communicate with mesenteric lymph nodes, fact that allows the intraperitoneal cancer to spread to this region.

A concentrated group of lymph nodes are located in the region of the root of renal and splenic artery and they form an upper para-aortic chain. These lymph nodes receive lymph directly from testis and ovaries [52]. Any malignant tumor in these organs can metastasize here first. When para-aortic lymph nodes are involved in these kind of processes, they can affect the ureters, due to the mass effect, leading to ureterohydronephrosis and eventually renal displacement, with high risk of secondary renal failure [53], documented by pyelographic examination. Commonly, primary or metastatic retroperitoneal lymph nodes that are affected can not produce a palpable abdominal mass [54-58].

\section{Conclusions}

The retroperitoneum can have a large spectrum of rare pathologies, including benign and malignant tumors. Most patients usually present in advanced stages, when the tumor becomes palpable or once they have reached a significant size, leading to associated signs and symptoms. Complete surgical resection is the potential curative treatment modality at this time for retroperitoneal neoplasms and is best managed in high-volume centers by a multidisciplinary team. Local recurrence is present in a large proportion of patients. Complete surgical resection and tumor grade remain the most important predictors of local recurrence and disease-specific survival. Further research is required to define the role of radiotherapy and to develop new biological therapies, to target the various molecular pathways for the treatment of retroperitoneal cancers.

\section{References}

1.HANSMANN, G. H., BUDD, J. W., J. Amer. Med. Assoc., 98, no. 1, 1932, p. 6.

2.ENGEL, W. J .,Arch. Surg., 70, no. 2, 1955, p. 156.

3.FISHER, C., VAN DEN BERG, E., MOLENAAR, W.M., World Health Organization Classification of Tumors, 2002, p.1000.

4.GUILLOU, L., FOLPE, A.L., Fibroblastic and Fibrohistiocytic Tumors, Bone and Soft Tissue Pathology, 2009, p. 40.

5.PETRE, I., ILIE, M., BLEOTU, C., SANDRU, V., PLOTOGEA, O., CONSTANTINESCU, G., Arch Balk Med Union, 53, no. 1, 2018, p. 47-56. 6.COINDRE, J.M., Arch. Pathol. Lab. Med., 130, no 10, 2006, p. 1448. 7.CORMIER, J.N., POLLOCK, R.E., Cancer J. Clin., 54, no 2, 2004, p. 94.

8.COINDRE, J.M., NGUYEN, B.B., BONICHON, F., DE MASCAREL, I., TROJANI, M., Cancer, 61, no. 11, 1988, p. 2305.

9.THWAY, K., Clin.Oncol., 21, no. 9, 2009, p. 695.

10.BAHRAMI, A., FOLPE, A.L., Amer. J. Surg. Pathol., 34, no. 10, 2010, p. 1504.

11.PICCI, P., MANFRINI, M., FABBRI, N., GAMBAROTTI, M., VANEL, D., Atlas of Musculoskeletal Tumors and Tumor-like Lesions, 2014, p. 307.

12.*** ESMO/EUROPEAN SARCOMA NETWORK WORKING GROUP SOFT TISSUE AND VISCERAL SARCOMAS, Ann Oncol, 25, suppl 3, 2014 , p. 102.

13.BAO, Q., NIESS, H., DJAFARZADEH, R., ZHAO, Y., SCHWARZ, B., ANGELE, M.K., JAUCH, K.W., NELSON, P.J., BRUNS, C.J., Targeted Oncol., 9, no. 3, 2014, p. 251. 
14.DJAFARZADEH, R., NOTOHAMIPRODJ O, S., RIETH, N., HOFSTETTER, M., NOESSNER, E., NELSON P.J ., J Investigative Derm., 133, no. 3, 2013, p. 803.

15.SHAIN, K.H., DALTON, W.S., Molecular Cancer Therapeutics, 1, no. 1, 2001, p. 69.

16.WEISS, S.W., GOLDBLUM, J.R., Enzinger\& Weiss's Soft Tissue Tumors, 2008, p. 100.

17.MIETTINEN, M., FETSCH, J.F., Histopathol., 48, no. 1, 2006, p. 97. 18.PRICE, N.D., TRENT, J., EL-NAGGAR, A.K., et al., Proceedings of the National Academy of Sciences of the United States of America, 104, no. 9, 2007, p. 3414.

19.SVARVAR, C., BOHLING, T., BERLIN, O., et al., Cancer, 109, no. 2, 2007, p. 282.

20.J AQUES, D.P., COIT, D.G., HAJ DU, S.I., BRENNAN, M.F., Ann Surg, 212, no. 1, 1990, p.51.

21.LEWIS, J.J., LEUNG, D., WOODRUFF, J.M., BRENNAN, M.F., Ann Surg, 228, no.3, 1998, p. 355.

22.SINGER, S., CORSON, J.M., DEMETRI, G.D., et al., Ann Surg, 221, no. 2, 1995, p. 185.

23.STORM, F.K., MAHVI, D.M., Ann Surg, 214, no.1, 1991, p. 2.

24.CATTON, C.N., O'SULLIVAN, B., KOTWALL, C., et al., Int J Radiat Oncol Biol Phys, 29, no. 5, 1994, p. 1005.

25.CHECHERITA, I.A., DAVID, C.R., DIACONU, V., CIOCALTEU, A., LASCAR, I., Rom J Morphol Embryol., 52, nr. 3 Suppl., 2011, p. 10471050.

26.LICHT, M. R., NOVICK, A. C., J Urol, 149, no. 1, 1993, p. 1.

27.MOLL, V., BECHT, E., ZIEGLER, M., J Urol, 150, no. 2, 1993, p. 319. 28.CHECHERITA, I.A., TURCU, F., DRAGOMIRESCU, R.F., CIOCALTEU, A.,. Rom J Morphol Embryol., 51, nr. 1, 2010, p. 21-26.

29.HERR, H. W., J Urol, 161, no.1, 1999, p. 33.

30.AMIN, M. B., CORLESS, C. L., RENSHAW, A. A., et al., Am J Surg Pathol, 21, no. 6, 1997, p. 621.

31.LERNER, S. E., HAWKINS, C. A., BLUTE, M. L. et al., J Urol, 155, no. 6, 1996, p. 1868.

32.BRENNAN, M.F., Cancer J Clin, 37, no. 2, 1987, p. 348.

33.MACFARLANE, D.A., Ann R Coll Surg Engl, 23, no. 3, 1958, p. 155. 34.POIANA, C., CHIRITA, C., CARSOTE, M., BULATA, R., IOSIF, C., PETRESCU, R., VERZEA, S., STANESCU, B., Chirurgia (Bucharest), 104, nr. 6, 2009, p. 753-756.

35.LUTON, J., CERDAS, S., LINE, B., et al., N Engl J Med, 322, no. 17, 1990, p. 1195.

36.PADURARU, D.N., PITURU, S.M., BOLOCAN, A., MARIN, I., ANDRONIC, O., Arch Balk Med Union, 52, no. 4, 2017, p. 414-421.

37.TIGLIS, M., GRINTESCU, I.C., NEAGU, T.P., TURCU, F.L., COCOLOS, A.M., GRINTESCU, I.M., Rev Chim. (Bucharest), 69, no. 2, 2018, p. 391395.

38.PETRE-CIUDIN, V., PETRE-CIUDIN, C., VELNIC, A.A., HANGANU, B., MANOILESCU, I., CRAUCIUC, D., IOAN, B.G., Arch Balk Med Union, 52, no. 4, 2017, p. 434-438.

39.FANG, Y., YAO, Q., CHEN, Z., et al., Medical Science Monitor, 19, 2013, p. 916.
40.MOGOANTA, S.S., COSTACHE, A, MUTIU, G., BUNGAU, S.G., GHILUSI, M., GROSU, F., VASILE, M., VILCEA, I.D., GHERGHINESCU, M.C., MOGOANTA, L., ION, D.A., Rom. J. Morphol. Embriol., 56, no. 2 Suppl., 2015, p. 511.

41.WOLFGANG, C.L., HERMAN,J.M., LAHERU, D.A. et al., A Cancer Journal for Clinicians, 63, no. 5, 2013, p. 318.

42.PERIDE, I., CHECHERITA, I.A., CIOCALTEU, A., LASCAR, I., Chirurgia (Bucharest), 106, no. 1, 2011, p. 83-89.

43.NEESSE, A., MICHL, P., FRESE, K.K., et al., Gut, 60, no. 6, 2011, p. 861.

44.TOTOLICI, B.D., NEAMTU, C., BODOG, F.D., BUNGAU, S.G., GOLDIS, D.S., MATEI, M., ANDERCOU, A.O., AMZA, O.L., GYORI, Z., COLDEA, L., Rom. J. Morphol. Embriol., 58, no. 1, 2017, p. 267.

45.TOTAN, M., GLIGOR, F.G., BOJ ITA, M., GRIGORE, C., GRIGORE, C., Rom. Rev. Lab. Med., 21, no. 1, 2013, p. 39.

46.PALLAG, A., ROSCA, E., TIT, D.M., MUTIU G., BUNGAU, S.G., POP, O.L., Rom. J. Morphol. Embriol., 56, no. 3, 2015, p. 1103.

47.GRIGORE, N., TOTAN, M., PIRVUT, V., CERNUSCA-MITARIU, S.I., CHICEA, R., SAVA, M., HASEGAN, A., Rev. Chim. (Bucharest), 68, no. 7, 2017, p. 1453.

48.GRIGORE, N., PIRVUT, V., TOTAN, M., BRATU, D., CERNUSCAMITARIU, S.I., CERNUSCA-MITARIU, M., CHICEA, R., SAVA, M., HASEGAN, A., Rev. Chim. (Bucharest), 68, no. 6, 2017. p. 1285

49.BUMBU, A., PASCA, B., TIT, D. M., BUNGAU, S., BUMBU, G., Farmacia, 64, no. 3, 2016, p. 419.

50.SOARES, K.C., ZHENG, L., EDIL, B., JAFFEE, E.M., Cancer J ournal, 18, no. 6, 2012, p. 642.

51.MIREA, D., MIREA, L.E., NITIPIR, C., TIGLIS, M., GRINTESCU, I.C., NEAGU, T.P., MOGOANTA, C.A., GRINTESCU, I.M., Rom J Morphol Embryol., 58, 2017, p. 3

52.GHEORGHISAN-GALATEANU, A., TERZEA, D.C., CARSOTE, M., POIANA, C., J Ovarian Res., 6, nr. 1, 2013, p. 28.

53.RADULESCU, D., PERIDE, I., PETCU, L.C., NICULAE, A., CHECHERITA, I.A., Ultrasound Med Biol., 44, no. 12, 2018, p. 25562568.

54.HONORE, C., FARON, M., MIR, O., et al., J. Surg. Oncol., 118, no. 8, 2018, p. 1318.

55.ABDEL-DAIM, M.M., ABO-EL-SOOUD, K., ALEYA, L., BUNGAU, S.G., NAJDA, A., SALUJA, R., Oxid. Med. Cell. Longev., 2018, ID 6276438. doi: $10.1155 / 2018 / 6276438$.

56.GEAVLETE, B.F., BRINZEA, A., CHECHERITA, I.A., ZURAC, S.A., GEORGESCU, D.A., BASTIAN, A.E., ENE, C.V., BULAI, C.A., GEAVLETE, D.O., ZAHARIA, M.R., GEAVLETE, P.A., J Morphol Embryol., 56, no. 3, 2015, p. 1069-1076.

57.ENDRES, L.,TIT, D.M., BUNGAU, S., CIOCA, G., ABDEL-DAIM, M., BUHAS, C., POP, O., SAVA, C., Rev. Chim.(Bucharest), 69, no. 12, 2018, p. 3675-3679.

58.MEHEDINTU, C., BRATILA, E., BERCEANU, C., CIRSTOIU, M.M., BARAC, R. I., ANDREESCU, C.V., BADIU D.C., GALES L., ZGURA A., BUMBU A.G., Rev. Chim.(Bucharest), 69, no. 11, 2018, p. 3133.

Manuscript received: 18.08 .2018 